\title{
Effect of Asperagillus awamori on Alloxan-induced Mouse Hyperglycemia
}

\author{
Shota Masuda ${ }^{1}$, Yoshinao Okachi ${ }^{1}$, Takumi Hirao ${ }^{1}$, Kosuke Matsuoka ${ }^{1}$, Ryusei Miura ${ }^{1}$, Shunya Miyoshi ${ }^{1}$, \\ Takayuki Murakami ${ }^{2}$, Junji Inoue ${ }^{2}$, Kohji Ishihara ${ }^{1} \&$ Noriyoshi Masuoka $^{1,3}$ \\ ${ }^{1}$ Department of Life Science, Okayama University of Science, 1-1 Ridai-cho, Kita-ku, Okayama 700-0005, \\ Japan \\ ${ }^{2}$ Ahjikan Co. Ltd., 7-3-9 Nishi-ku, Hiroshima 733-8677, Japan \\ ${ }^{3}$ CDW Life Science Lab, Okayama Research Park Incubation Center, 5303 Haga, Kita-ku, Okayama 701-1221, \\ Japan \\ Correspondence: Noriyoshi Masuoka, CDW Life Science Lab, Okayama Research Park Incubation Center, 5303 \\ Haga, Kita-ku, Okayama 701-1221, Japan. E-mail: masuokan@ms11.megaegg.ne.jp
}

Received: September 2, $2017 \quad$ Accepted: September 30, $2017 \quad$ Online Published: October 10, 2017

doi:10.5539/jfr.v6n6p29

URL: https://doi.org/10.5539/jfr.v6n6p29

\begin{abstract}
Problem statement: Though alloxan-induced mouse hyperglycemia was ameliorated by feeding of $5 \%$ Asperagillus awamori (A. awamori)-fermented burdock root diet (fermented burdock diet), it is unclear whether the anti-hyperglycemia activity is due to $A$. awamori or antioxidant activity induced by the fermentation.

Methods: A $0.05 \%$ A. awamori diet was prepared. Acatalasemic mice, having a quite low catalase activity in blood, were divided three groups, and each group fed control, A. awamori and the fermented burdock diets for 14 weeks, separately. Then, alloxan monohydrate $(200 \mathrm{mg} / \mathrm{kg}$ of body weight $)$ was intraperitoneally administrated to each mouse. Glucose, insulin, C-peptide contents in blood and glucose tolerance tests (GTTs) were examined.

Results: Incidence of alloxan-induced hyperglycemia in acatalasemic mice maintained with the A. awamori diet or the fermented burdock diet was low (20 or $25 \%$ ) compared to that $(75 \%)$ maintained with the control diet. Feeding the A. awamori diet ameliorated insulin, C-peptide in blood and GTT like as mice fed the fermented burdock diet. It indicated that A. awamori in these diets plays an important role for the prevention of alloxan-induced hyperglycemia.
\end{abstract}

Conclusions: It is suggested that $A$. awamori has the anti-hyperglycemia activity.

Keywords: hyperglycemia, insulin, C-peptide, alloxan, Asperagillus awamori

\section{Introduction}

Diabetes mellitus is a syndrome characterized by hyperglycemia, more than a desirable level of glucose in blood (Taylor, 1995). The morbidity causes blindness, renal failure and amputation, and diabetes is a worldwide disease and one of the major causes of death. It was reported that 171 million people suffer from diabetes at 2000 and 366 million people will do at 2030 (Wild et al., 2004). Alloxan is a diabetogenic drug for animals, and alloxan with reducing agents in the body generates reactive oxygen species to induce oxidative stress. These oxygen species selectively injure $\beta$-cells in the pancreas so as to cause hyperglycemia as like diabetes Type 1 (Szkudelski, 2001; Lenzen, 2008). Many researchers interest in finding anti-hyperglycemic compounds or products to prevent this alloxan-induced hyperglycemia (Perumal et al., 2014; Oloyede et al., 2015). As we found that acatalasemia (very low catalase activity, hereditary catalase deficiency) mice induced diabetes mellitus with smaller amount of alloxan than normal mice, we also pursued anti-hyperglycemia compounds using alloxan-induced acatalasemic mice (Takemoto et al., 2009; Kamimura et al., 2013). Burdock root, Artium lappa, is a popular vegetable in Japan and Korea. It contains a considerable amount of polyphenols such as chlorogenic acid, caffeoylquinic acid, hydroxycinnamoylquinic acids and related compounds and indicates antioxidant activity (Maruta, Kawabata \& Niki, 1995; Lin \& Harnly, 2008). Okazaki et al. (2013) prepared A. awamori-fermented burdock root to improve the functional property of burdock, and indicated that the intake improved intestinal environment and suppressed obesity in rats fed a high fat-diet. Fermentation of burdock root 
with A. awamori indicated increases of 1, 1-diphenyl-2-picryhydrazyl (DPPH) scavenging activity and polyphenol contents (Doi et al., 2015), and feeding of 5\% A. awamori-fermented burdock root diet ameliorated mouse hyperglycemia induced by alloxan (Doi et al., 2013; Takemoto et al., 2014). As feeding of $5 \%$ raw burdock root diet did not ameliorate mouse hyperglycemia, we suggested that $A$. awamori plays an important role for preventing alloxan-induced mouse hyperglycemia. As it was suggested that the intake of antioxidants can ameliorate oxidative stresses (Yamaoka et al., 2008; Choi et al., 2009), we prepared $0.05 \%$ A awamori diet and examined the effect on alloxan-induced mouse hyperglycemia to confirm anti-hyperglycemia effect of $A$. awamori.

\section{Materials and Methods}

\subsection{Materials}

Normal mice $\left(\mathrm{C} 3 \mathrm{H} / \mathrm{AnL} \mathrm{CS}^{\mathrm{a}} \mathrm{CS}^{\mathrm{a}}\right)$ and acatalasemia mice $\left(\mathrm{C} 3 \mathrm{H} / \mathrm{AnL} \mathrm{CS}^{\mathrm{b}} \mathrm{CS}^{\mathrm{b}}\right)$ established by Feinstein, Braun, \& Howard (1967) were bred. Both male mice were maintained on a laboratory diet (CE-2 diet, Clea Japan, Tokyo) and water ad libitum until the start of the experiments. Catalase activity in the mouse erythrocytes was measured according to previous method (Masuoka et al., 1996) and calculated as the difference between the hydrogen peroxide removal rate by hemolysate and the rate $(0.73 \mu \mathrm{mol} / \mathrm{s} / \mathrm{g}$ of hemoglobin) by hemoglobin (Takemoto et al., 2009).

Control diet (AIN-93M), A. awamori and A. awamori-fermented burdock diets were prepared by Ahjikan Co. Ltd (Hiroshima, Japan). A. awamori diet was prepared by mixing components (in Table 1) with 0.1 volume of water and then dried using air drying oven at $50^{\circ} \mathrm{C}$. A. awamori-fermented burdock diet was prepared according to the procedure (Okazaki et al., 2013; Doi et al., 2015). Tablets of these diets $(1.3 \times 2 \mathrm{~cm})$ were prepared and stored at $-20^{\circ} \mathrm{C}$ until use.

Table 1. Composition of prepared diets $(\%, \mathrm{w} / \mathrm{w})$

\begin{tabular}{llcc}
\hline Component compounds & Control diet & Fermented burdock diet & A. awamori diet \\
\hline Corn starch & 47.0692 & 42.0692 & 47.0192 \\
Milk casein & 14.0 & 14.0 & 14.0 \\
a-Corn starch & 15.0 & 15.0 & 15.0 \\
Sucrose & 10.0 & 10.0 & 10.0 \\
Soybean oil & 4.0 & 4.0 & 4.0 \\
Cellulose powders & 5.0 & 5.0 & 5.0 \\
Mineral mixture (AIN-93M) & 3.5 & 3.5 & 3.5 \\
Vitamin mixture(AIN-93VX) & 1.0 & 1.0 & 1.0 \\
L-cysteine & 0.18 & 0.18 & 0.18 \\
Choline & 0.25 & 0.25 & 0.25 \\
$t$-Butylhydroquinone & 0.0008 & 0.0008 & 0.0008 \\
Fermented burdock root* & 0.0 & 5.0 & 0.0 \\
Aspergillus awamori spores & 0.0 & 0.0 & 0.05 \\
\hline
\end{tabular}

Control diet, AIN-93M, was prepared according to the method (Reeves, Nielson, \& Fahey, 1993).

* indicates A. awamori-fermented burdock root powders.

\subsection{Animal Experiments}

The experimental procedure was approved by the Ethics Review Committees for Animal Experimentation of Okayama University of Science. Alloxan monohydrate $(200 \mathrm{mg} / \mathrm{kg}$ of body weight) was intraperitoneally administrated to induce hyperglycemia for acatalasemic mice (Takemoto et al, 2009).

Acatalasemic mice $(n=25)$ and normal mice $(n=17)$ were used at the age of 14 to 15 weeks old (body weight was between 22 and $37 \mathrm{~g}$ ) and were housed in a group of four. Acatalasemic and normal mice were divided into three kinds of diet groups, respectively. Mice in each group fed control diet, A. awamori and the fermented burdock diets ad libitum for 14 weeks. Then, each group divided two groups, alloxan administration and the control groups. Alloxan monohydrate was dissolved with phosphate buffered saline (PBS), and the solution was intraperitoneally administrated $(200 \mathrm{mg} / \mathrm{kg}$ of body weight). To mice in the control group, PBS was injected. Mice in each diet group were maintained on the same diet for one more week. After five days, mice were fasted for $20 \mathrm{hrs}$, and GTTs were carried out. After 2 days from GTT, mice fasted were killed under diethyl ether anesthesia. Each mouse blood was collected in test tube containing heparin as the anticoagulant from heart. Blood was centrifuged, and the plasma was isolated. Insulin and C-peptide levels in plasma were examined. 
Pancreas in each mouse was isolated, and the sections were prepared for microscopic studies.

\subsection{Assay of Blood Glucose}

After fasting, glucose content in the blood obtained from the tail was determined. As the blood volume for the determination of blood glucose was quite small (approximately $2 \mu \mathrm{L}$ ), the glucose contents in blood were measured with a "Glucose-Test-Ace R" apparatus (Sanwa Kagaku Kenkyusho Co., Nagoya, Japan) applying a glucose oxidase method.

\subsection{GTT}

After fasting, a forty percent aqueous glucose solution $(5 \mathrm{~mL} / \mathrm{kg}$ of body weight) was intraperitoneally administered to each mouse (Gao et al., 2007). At 0 and $30 \mathrm{~min}$ before and 15, 30, 60, 90 and $120 \mathrm{~min}$ after the administration, glucose contents in the blood were measured.

\subsection{Determination of the Insulin and C-peptide Levels in Blood}

The insulin and C-peptide plasma levels were determined using Mouse Insulin and C-peptide ELISA KITs (U-type) (Shibayagi, Gunma, Japan). Each determination was carried out according to the manufacturer's instructions. Biotin-conjugated anti-insulin antibody $(45 \mu \mathrm{L})$ was added to each well in an antibody-coated 96-well plate. To the well, $5 \mu \mathrm{L}$ of the sample or standard solution was added and reacted for $2 \mathrm{hrs}$. Then $50 \mu \mathrm{L}$ of peroxidase-conjugated avidin solution was added and reacted for $30 \mathrm{~min}$. Chromogenic substrate solution (50 $\mu \mathrm{L}$ ) was added and reacted for $30 \mathrm{~min}$. The reaction was stopped and the absorbance at $450 \mathrm{~nm}$ (sub-wave length, $620 \mathrm{~nm}$ ) was recorded.

\subsection{Microscopic Studies of Pancreatic Tissues in the Mice Treated with Alloxan}

Pancreatic tissues were isolated, fixed in Bouin's fluid and embedded in paraffin. Serial sections $(6 \mu \mathrm{m})$ were cut from each paraffin-embedded tissue block, and several sections were stained with hematoxylin-eosin and mouse anti-insulin antibody (Santa Cruz Biotechnology) using the Vectastain Elite ABC Rabbit IgG Kit for visualization by light microscopy. The islets and other cells were recorded with a FX380 CCD Camera and a microscope (Olympus, Tokyo, Japan).

\subsection{Statistical Analysis}

Student's t-test was used to evaluate the statistical significance of difference. The difference was considered significant when $\mathrm{p}<0.05$.

\section{Results}

\subsection{Catalase Activity in Mouse Blood}

The catalase activity of acatalasemic mice in blood at $25{ }^{\circ} \mathrm{C}$ was $0.15 \pm 0.07 \mu \mathrm{mol} / \mathrm{s} / \mathrm{g}$ of $\mathrm{Hb}$, and that of normal mice was $6.77 \pm 0.62 \mu \mathrm{mol} / \mathrm{s} / \mathrm{g}$ of $\mathrm{Hb} .(\mathrm{p}<0.001)$

\subsection{Body Weights Maintained on A. Awamori, the Fermented Burdock and the Control Diets}

The average mouse body weights were indicated in Figure 1. There is no difference among body weights by feeding control diet, A. awamori diet and the fermented burdock diet.

(A)

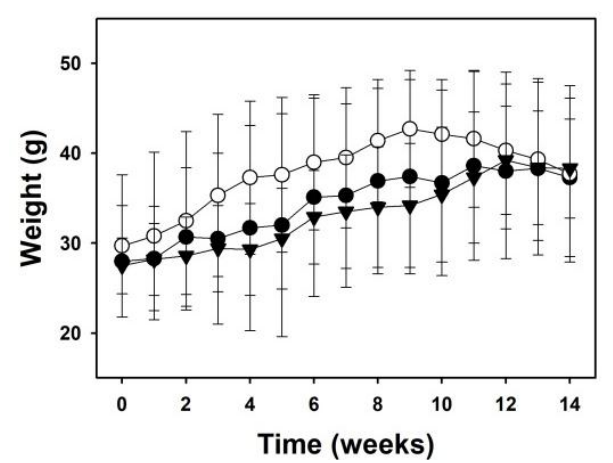

(B)

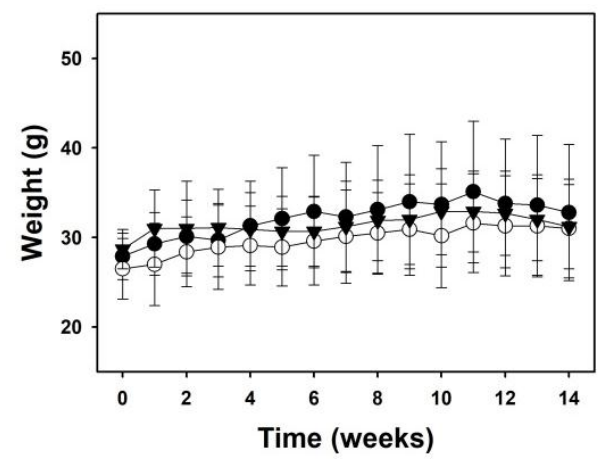

Figure 1. Body weight changes of normal and acatalasemic mice by feeding control, A. awamori and the fermented burdock diets

(A) Normal mice, (B) acatalasemic mice. Open circle (०) indicated mice fed control diet, closed circle (•): mice fed A. awamori diet, triangle $(\boldsymbol{\nabla})$ : mice fed fermented burdock diet. 


\subsection{Incidence of Hyperglycemia Maintained on Each Diet after Alloxan Administration}

After feeding each diet for 14 weeks, alloxan was administrated. Incidence of hyperglycemia was examined after 5 days from alloxan administration (Table 2). It indicated that the incidence of acatalasemic mice fed A. awamori diet is low as the mice fed fermented burdock diet.

Table 2. Incidence of hyperglycemia after alloxan administration

\begin{tabular}{lcccc}
\hline \multirow{2}{*}{ Mice } & Alloxan & \multicolumn{3}{c}{ Incidence of hyperglycemia \% } \\
\cline { 3 - 5 } & $(\mathrm{mg} / \mathrm{kg})$ & Control diet (n) & A. awamori diet (n) & Fermented burdock diet (n) \\
\hline Normal & 200 & $0(4)$ & $0(4)$ & $0(5)$ \\
Acatalasemia & 200 & $75(4)$ & $20(5)$ & $25(4)$ \\
\hline
\end{tabular}

" $n$ " in parentheses indicates number of mice. Hyperglycemia is $>121 \mathrm{mg} / \mathrm{dl}$ of blood.

\subsection{Effect of the A. awamori Diet on GTT}

GTTs of normal (A) and acatalasemic (B) mice treated with alloxan were indicated in Figure 2. GTT of normal mice treated with alloxan suggested that there is essentially no difference among them. However, in the case of acatalasemic mice, blood glucose in mice fed the control diet at 15, 30, 60, 90 and 120 min from glucose administration was higher than mice fed A. awamori and the fermented burdock diets. Blood glucose level of acatalasemic mice fed A. awamori diet or the fermented burdock diet after $120 \mathrm{~min}$ returned to the level before alloxan administration.

(A)

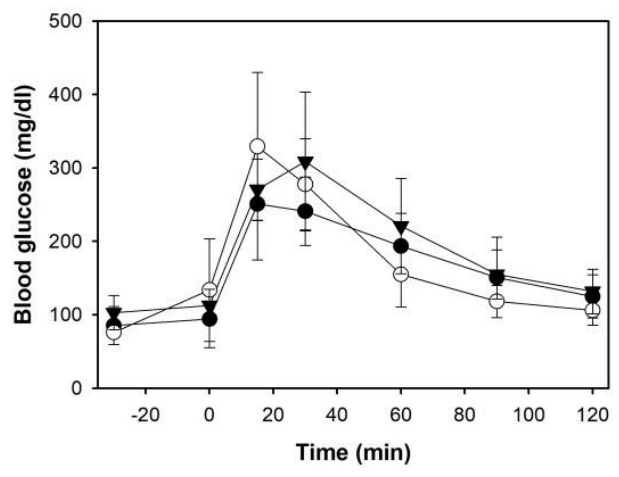

(B)

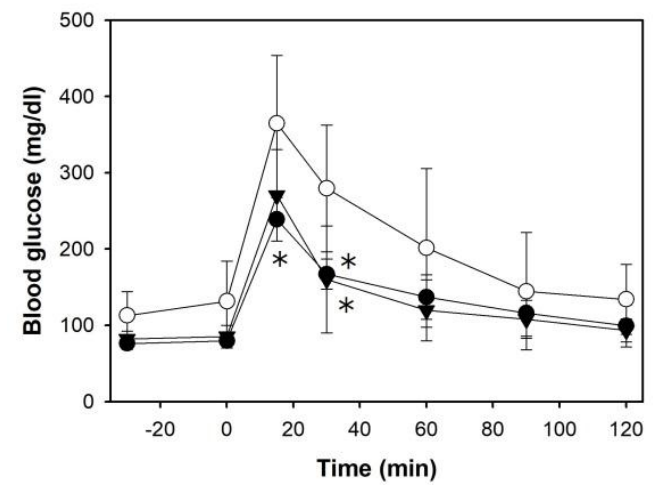

Figure 2. Glucose tolerance tests of alloxan administrated mice

(A): Normal mice, (B): acatalasemic mice. Glucose was loaded at $0 \mathrm{~min}$. Open circle (०) indicated mice fed control diet, closed circle $(\bullet)$ : mice fed A. awamori diet, triangle $(\boldsymbol{\nabla})$ : mice fed the fermented burdock diet. * indicated $\mathrm{P}<0.05$, compared to the control diet.

\subsection{Insulin and C-peptide Concentrations in Acatalasemic Blood}

After alloxan administration, insulin concentrations in acatalasemic mouse blood decreased (data not indicated). Concentration of C-peptide from acatalasemic mice fed the control diet significantly decreased from $740 \pm 101$ $\mathrm{pg} / \mathrm{mL}$ to $572 \pm 47 \mathrm{pg} / \mathrm{mL}(\mathrm{P}=0.014)$ but the concentration from mice fed A. awamori diet and the fermented burdock diet did not (from $645 \pm 95$ to $645 \pm 65 \mathrm{pg} / \mathrm{mL}$ and from $651 \pm 61$ to $631 \pm 52 \mathrm{pg} / \mathrm{mL}$, respectively).

\subsection{Microscopic Examination of Pancreatic Tissues in Mice Treated with Alloxan}

In the case of acatalasemic mice, insulin-positive cell numbers isolated from the mice were decreased by alloxan administration and were hardly affected by diets (data not indicated). By alloxan administration, cell size from the mice fed the control diet was decreased to $80 \pm 10 \%,(\mathrm{p}=0.055)$ compared to the size at PBS administration, but the sizes isolated from the mice fed A. awamori diet and the fermented burdock diet were not $(97 \pm 7$ and $101 \pm 10 \%)$.

\section{Discussion}

Alloxan induces oxidative stress and causes hyperglycemia. When mice fed A. awamori-fermented burdock diet, incidence of hyperglycemia in normal and acatalasemic mice was lower than that in mice fed the control diet after alloxan administration (Doi et al., 2013; Takemoto et al., 2014), and the raw burdock diet does not indicate 
anti-hyperglycemia activity (Doi et al., 2015). However, the fermentation of burdock root with A. awamori induced increase of DPPH scavenging activity and polyphenol contents, and the increased antioxidant activity may ameliorate alloxan-induced hyperglycemia. A $0.05 \%$ A. awamori diet was prepared and the feeding was examined to confirm the anti-hyperglycemia activity of A. awamori. Feeding of the A. awamori diet suppressed the incidence of hyperglycemia and improved the GTT, C-peptide and insulin-positive cell size compared to feeding of the control diet. The result indicated that hyperglycemia induced by alloxan administration was ameliorated by feeding of only A. awamori. Several researchers reported that dietary intake of A. awamori improved an intestinal environment and induced increase of $\alpha$-tocopherol (vitamin E) level in their blood and muscles to affect the lipid and protein metabolism (El-Deep et al., 2014; Saleh et al., 2013, 2014). As the intake of vitamin E improved mouse hyperglycemia caused by alloxan and vitamin $\mathrm{E}$ improved insulin release from pancreas damaged by alloxan (Kamimura et al., 2013; Takemoto, Doi, \& Masuoka, 2016), we deduced that $A$. awamori is an effective probiotic and increases vitamin $\mathrm{E}$ to ameliorate hyperglycemia induced by oxidative stress. Therefore, A. awamori may be likely to be applicable as a supplement if untoward side effects are not observed.

\section{References}

Choi, E. J., Bae, S. C., Yu, R., Youn, J., \& Sung, M. K. (2009). Dietary vitamin E and quercetin modulate inflammatory responses of collagen-induced arthritis in mice. J. Med. Food, 12, 770-775. https://doi.org/10.1089/jmf.2008.1246.

Doi, W., Takemoto, K., Ansai, K., Ishihara, K., Murakami, T., Inoue, J., Oda, S., \& Masuoka, N. (2013). Effect of fermented-burdock on alloxan-induced mouse diabetes. Okayama Rika Daigaku Kiyo, 49, 11-17.

Doi, W., Asada, Y., Ohno, A., Okuda, Y., Masuda, S., Matsumoto, A., Mori C., Agarie T., Ishihara K., Murakami, T., \& Masuoka, N. (2015) Effect of burdock root and the fermented product on alloxan-induced mouse hyperglycemia. Journal of Food Research, 4(4), 10-17.

El-Deep, M. H., Ijiri, D., Eid, Y. Z., Yamanaka, H., \& Ohtsuka, A. (2014) Effects of dietary Supplementation with Aspergillus Awamori on growth performance and antioxidative status of broiler chickens exposed to high ambient temperature. Japan Poultry Science Association, 51, 281-288. https://doi.org/10.2141/2013/jpsa.0130154

Feinstein, R. N., Braun, J. T., \& Howard, J. B. (1967). Acatalasemic and hypocatalasemic mouse mutants. II. Mutational variations in blood and solid tissue catalases. Arch. Biochem. Biophys., 120, 165-9. https://doi.org/10.1016/0003-9861(67)90609-1

Gao, D., Li, Q., Liu, Z., Li, Y., Liu, Z., Fan, Y., Li, K., Han, Z., \& Li, J. (2007). Hypoglycemic effects and mechanisms of action of Cortex Lycii Radicis on alloxan-induced diabetic mice. Yakugaku Zasshi, 127, 1715-1721.

Kamimura, W., Doi, W., Takemoto, K., Ishihara, K., Wang, D. H., Sugiyama, H., Oda, S., \& Masuoka, N. (2013). Effect of vitamin E on alloxan-induced mouse diabetes. Clin. Biochem., 46, 795-798. https://doi.org/10.1016/j.clinbiochem.2013.02.016

Lenzen, S. (2008). The mechanisms of alloxan- and streptozotocin-induced diabetes. Diabetologia 51, 216-226.

Lin, L-Z., \& Harnly. J. M. (2008). Identification of hydroxycinnamoylquinic acids of arnica flowers and burdock roots using a standardized LC-DAD-ESI/MS profiling method. J. Agric. Food Chem., 56, 10105-10114. https://doi.org/10.1021/jf802412m

Maruta, Y., Kawabata, J., \& Niki, R. (1995). Antioxidative caffeoylquinic acid derivatives in the roots of burdock (Arctium lappa L.). J. Agric. Food Chem., 43, 2592-2595. https://doi.org/10.1021/jf00058a007

Masuoka, N., Wakimoto, M., Ubuka, T., \& Nakano, T. (1996). Spectrophotometric determination of hydrogen peroxide: catalase activity and rates of hydrogen peroxide removal by erythrocytes. Clin. Chim. Acta, 254, 101-112. https://doi.org/10.1016/0009-8981(96)06374-7

Okazaki, Y., Sitanggang, N. V., Sato, S., Ohnishi, N., Inoue, J., Iguchi, T., Watanabe, T., Tomotake, H., Harada, K., \& Kato, N. (2013). Burdock fermented by Aspergillus awamori elevates cecal Bifidobacterium, and reduces fecal deoxycholic acid and adipose tissue weight in rats fed a high-fat diet. Biosci. Biotechnol. Biochem., 77, 53-57. https://doi.org/10.1271/bbb.120551

Oloyede, H. O., Bello, T. O., Ajiboye, T. O., \& Salawu, M. O. (2015). Antidiabetic and antidyslipidemic activities of aqueous leaf extract of Dioscoreophyllum cumminsii (Stapf) Diels in alloxan-induced diabetic rats. J. Ethnophamacol., 166, 313-322. https://doi.org/10.1016/j.jep2015.02.049 
Perumal, P. S., Anaswara, P. V., Muthurama, A., \& Krishan, S. (2014). Therapeutic potency of saponin rich aqueous extract of Scoparia dulcis L. in alloxan induced diabetes in rats. Pharmacological study, 35, 211-217. https://doi.org/10.4103/0974-8520.146261

Reeves, P. G., Nielson, F. H., \& Fahey, G. C. Jr. (1993). AIN-93 purified diets for laboratory rodents: final report of the American Institute of Nutrition and hoc writing committee on the reformulation of the AIN-73A rodent diet. J. Nutr., 123, 1939-1951.

Saleh, A. A., Ohtsuka, A., Yamamoto, M., \& Hayashi, K. (2013). Aspergillus awamori feeding modifies lipid metabolism in rats. Biomed Research International. https://doi.org/10.1155/2013/594393

Saleh, A. A., Amber, K., EI-Magd, M. A., Atta, M. S., Mohammed, A. A., Ragab, M. M., \& EI-Kader, H. A. (2014). Integrative effects of feeding Aspergillus awamori and fructooligosaccharide on growth performance and digestibility in broilers: promotion muscle protein metabolism. Biomed Research International. https://doi.org/10.1155/2014/946859

Szkudelski, T. (2001). The mechanism of alloxan and streptozotocin action in B cells of the rat pancreas. Physiol. Res., 50, 536-546.

Takemoto, K., Doi, W., Zukeran, A., Inoue, J., Ishihara, K., \& Masuoka, N. (2014). Effect of Aspergillus awamori-fermented burdock root on mouse diabetes induced by alloxan -prevention of cell apoptosis. Food and Nutrition Science, 5, 1554-1560. https://doi.org/10.4236/fns.2014.516168

Takemoto, K., Tanaka, M., Iwata, H., Nishihara, R., Ishihara, K., Wang, D. H., Ogino, K., Taniuchi, K., \&Masuoka, N. (2009), Low catalase activity in blood is associated with the diabetes caused by alloxan. Clin. Chim. Acta, 407, 43-46. https://doi.org/10.1016/j.cca.2009.06.028

Takemoto, K., Doi, W., \& Masuoka, N. (2016). Protective effect of vitamin E against alloxan-induced mouse hyperglycemia. Biochim Biophys Acta, 1862(4), 647-650.

Taylor, S. I. (1995). Diabetes Mellitus. In C. R. Scriver, A. L. Beaudet, W. S. Sly, \& D. Valle (Eds.) The metabolic and molecular bases of inherited disease Seventh edition (pp. 843-896)., McGrew-Hill, NY.

Wild, S., Roglic G., Green, A., Sicree, R., \& King, H. (2004) Global prevalence of diabetes: Estimates for the year 2000 and projections for 2030. Diabetes Care, 27, 1047-1053.

Yamaoka, S., Kim, H. S., Ogihara, T., Oue, S., Takitani, K., Yoshida, Y., \& Tamai, H. (2008). Severe vitamin E deficiency exacerbates acute hyperoxic lung injury associated with increased oxidative stress and inflammation. Free Radic. Res., 42, 602-612. https://doi.org/10.1080/10715760802189864

\section{Copyrights}

Copyright for this article is retained by the author(s), with first publication rights granted to the journal.

This is an open-access article distributed under the terms and conditions of the Creative Commons Attribution license (http://creativecommons.org/licenses/by/4.0/). 